\title{
The Impact of Trait Emotional Intelligence on Nursing Team Performance and Cohesiveness
}

\author{
JORDI QUOIDBACH AND MICHEL HANSENNE, PHD*
}

\begin{abstract}
Claims about the positive influence of emotional intelligence (EI) on work team performance are very numerous, both in commercial and scientific literature. However, despite the huge interest that media and business consultants put in El and its fast-growing use in organizations, there is very little empirical evidence to support these claims. In this study, we investigated the relationships between El, performance, and cohesiveness in 23 nursing teams. El was assessed using the modified version of the Schutte Emotional Intelligence Scale and cohesiveness with the Group Cohesiveness Scale. Finally, nursing team performance was measured at four different levels: job satisfaction, chief nursing executives' rating, turnover rate, and health care quality. Results showed that health care quality was positively correlated with emotion regulation. Emotion regulation was also positively correlated with group cohesiveness. Surprisingly, it also appears that emotion appraisal was negatively correlated with the health care quality provided by teams. These results suggest that El and, more specifically, Emotional Regulation may provide an interesting new way of enhancing nursing teams' cohesion and patient/client outcomes. (Index words: Emotional intelligence; Nursing team; Performance; Cohesion) J Prof Nurs 25:23-29, 2009. (c) 2009 Elsevier Inc. All rights reserved.
\end{abstract}

T HE MOST COMMON definition of emotional intelligence (EI) is the one proposed by Mayer and Salovey (1997, p. 5) who first developed the concept. According to these authors, EI is "the ability to perceive emotions, to access and generate emotions so as to assist thought, to understand emotions and emotional knowledge, and to reflectively regulate emotions so as to promote emotional and intellectual growth." When the EI concept was introduced, the interest remained limited to a small scientific community, until the publication of the book, Emotional Intelligence by Daniel Goleman (1995). Covering much of the existing literature on EI (Averill \& Nunley, 1992; Mayer, DiPaolo, \& Salovey, 1990; Mayer \& Stevens, 1994; Salovey \& Mayer, 1990), the book did not hesitate to claim the great benefits of EI on social relationship, job success, and health. Therefore, in short order, the general notion of EI became widely known, appearing in many magazine and newspaper

\footnotetext{
*University of Liège -Personality and Individual Differences Unit, B4000 Liège, Belgium.

Address correspondence to Dr. Quoidbach: University of LiègePersonality and Individual Differences Unit, 5 Bld du Rectorat (B32), B-4000 Liège, Belgium. E-mail: jquoidbach@ulg.ac.be 8755-7223/\$ - see front matter
}

articles (Mayer, Salovey, \& Caruso, 2000). Concurrently, several unsubstantiated claims have appeared in the popular literature and the media about the significant role of EI in the workplace (Zeidner, Matthews, \& Roberts, 2004). Thus, EI has been claimed to validly predict a variety of successful behaviors at work, at a level exceeding that of intelligence (Cooper \& Sawaf, 1997; Goleman, 1998; Hay Group, 2000; Weisinger, 1998). Nowadays, the use of EI for the purposes of career selection and job orientation has become a common practice in a great number of organizations, and according to a recent survey of benchmark practices in the United States, $80 \%$ of the major corporations are now trying to promote EI in their organization (Zeidner et al., 2004). In line with this enthusiasm, studies investigating EI in the nursing context are currently a topic of keen interest (Gerits, Derksen, Verbruggen, \& Katzko, 2005; Kooker, Shoultz, \& Codier, 2007; Landa, Lopez-Zafra, Martos, \& Guilar-Luzon, in press; Mcqueen, 2004; Montes-Berges \& Augusto, 2007).

\section{El and Performance}

Despite the huge amount of claims about El's positive influence on job performance and its fast-growing use in organizations, studies investigating relationships between EI and performance at individual level suggest 
that the current excitement surrounding the potential benefits from the use of EI in the workplace may be premature or even misplaced. Indeed, although EI appears to be related to performance and effective outcomes in some cases (Bachman, Stein, Campbell, \& Sitarenios, 2000; Bar-On, 1997; Dulewicz \& Higgs, 2000; Janovics \& Christiansen, 2001), the results are very limited and often contradictory (Zeidner et al., 2004). Moreover, the literature is replete with unsubstantiated generalizations, with much of the existing evidence bearing on the role of EI in occupational success either anecdotal or impressionistic and/or based on unpublished or in-house research (Barrett, Miguel, Tan, \& Hurd, 2001).

Few studies have investigated the relationships between EI and performance at group level. Jordan and Troth (2004) have found a link between EI and performance on a purely cognitive task at group level, although this link did not appear at individual level. According to these authors, EI and, more particularly, the ability to deal with one's own emotions, allowed team members to be more inclined to listen to alternative viewpoints and to look for superior solutions, without feeling threatened by the possibility of being wrong. Moreover, the same authors reported that the mean level of EI in a team affected its conflict resolution style: Teams with a high level of EI had a preference for collaborative conflict resolution strategies, whereas teams with low EI preferred avoiding strategies (Jordan \& Troth, 2002). Rapisarda (2002) also found a positive relationship between "empathy" (a subdimension of EI) and performance in student teams. Jordan, Ashkanasy, Härtel, and Hooper (2002) reported that self-learning student teams with lower average EI scores initially performed at a lower level than teams with high scores did, but eventually achieved the same level of performance over the 10 weeks of their study. Feyerherm and Rice (2002) demonstrated a relationship between EI and customer service teams. According to these authors, two of Mayer and Salovey's factors ("understanding emotions" and "managing emotions") were positively correlated with some performance measures related to customer service. However, they did not find any relationship between EI and team members' evaluation of performance, which led them to consider relationships between EI and performance a particularly complicated phenomenon.

Yet, although these first findings appear to be promising, these studies remain limited. Indeed, almost all of these studies are based on artificially created students' teams instead of real work teams, which can strongly bias the groups' dynamics. Then, the assessment of performance is rather rudimentary (e.g., self-report measures, problem solving, and decision making) and fails to reflect the multidimensional aspects of team performance (Dyer, 1995; Hackman, 1990; Katzenbach \& Smith, 1994; Savoie $\&$ Brunet, 2000). Indeed, most organizational tasks do not have clear right answers and cannot be resumed on a single quantifiable measurement (Hackman, 1987). According to Savoie and Brunet (2000), team perfor- mance assessment should include at least four different measures: (a) group experience quality, that is, the degree upon which group experience contributes to well-being and personal growth of team member; (b) team output, which relies on objective, measurable, and quantifiable performance criteria, for example, number of mistakes, waste ratio, or in the present context, percentage of technical acts meeting hygiene and safety standards; (c) team viability, that is, the capability of the team to continue to function as a unit; and (d) team legitimacy which relates to the appraisal of team's effectiveness by external actors who have close ties with it (e.g., managers, clients, suppliers, etc.). Finally, all of these previous studies only measure EI at the individual level, adding up these different scores into a mean team score. This way of proceeding is too simplistic. Indeed, can a single member with a very low EI not affect the whole team process? Would a group that is only composed of members with high-EI ratings always perform better than a mixed group? In addition to the mean score, it would be relevant to measure maximum and minimum EI scores along with team variance, following the example of Barrick, Stewart, Neubert, and Mount (1998) in their study on the impact of the personality at group level. Such an approach would allow answering these questions.

\section{EI and Cohesiveness}

Despite the very few studies on this topic, EI seems to be a facilitating factor for group cohesion. In this way, according to Prati, Douglas, Ferris, Ammeter, and Buckley (2003), team members who are emotionally intelligent form strong relationships and a solid team support system. Moreover, empathy that shares close relationships with EI (Miville, Carlozzi, Gushue, Schara, $\&$ Ueda, 2006) also has been argued to be an important characteristic necessary for team cohesion. Empathy can be defined as the sensitivity of an individual to the feelings and concerns of other social members (Abraham, 1999; George, 2000; Thoits, 1989). Thoits (1989) described empathy as a prosocial behavior, which is crucial to cohesive team function. The establishment of empathetic behaviors as a team norm will cause relationships to be built and the social network of the team to be formed (George, 2000). Finally, Rapisarda (2002) found significant positive correlations between the EI skills "empathy," "influence," and "achievement orientation" of Goleman's model and cohesiveness in students' teams.

\section{Aims and Hypotheses}

The purpose of this study was to explore among real-work nursing teams the relationships between EI, work team performance, and team cohesiveness firstly, by taking into account not only the mean score but also the minimum and maximal scores, as well as the groups' variance; secondly, by measuring the multiple aspects of team performance relying on an acknowledged theoretical model.

Based on the above discussion of EI at the group level, the following hypotheses are suggested: (1) Team EI will be related to group experience quality; (2) Team 
EI will be related to team output; (3) Team EI will be related to team viability; (4) Team EI will be related to team legitimacy; and (5) Team EI will be related to team cohesiveness.

\section{Method}

Participants

The participants in this study were 421 nurses, auxiliary nurses, and physiotherapists working in 23 nursing teams in the regional hospital center (Liege, Belgium). Medical doctors were not included in the study because they usually do not belong to a specific team and are not considered by nurses as part of their team. All the members in each team participated in our research. The average size of teams was 18.3 members $(S D=2.78)$. The smallest one was composed of 14 participants, and the biggest one of 23. Although at least $80 \%$ of the participants were women, no precise information on the composition of the sample was available because in such a real-work environment, participants feared to be recognized just by their age and gender and, therefore, questionnaires had to be totally anonymous.

\section{Measures}

Emotional Intelligence. The most appropriate method of measuring EI is currently an area of controversy. EI has been characterized by some researchers as a cognitive ability which should be assessed using problem-solving exercises (Mayer, Caruso, \& Salovey, 2000), whereas for other researchers, EI should be regarded as a dispositional tendency like personality which can be assessed by self-report questionnaire (Austin, Saklofske, Huang, \& McKenney, 2004; Bar-On, 2002; Petrides \& Furnham, 2003). Petrides and Furnham (2000) have suggested the terms ability EI and trait EI to distinguish the two measurement approaches. In this study the focus was on trait EI, and participants fulfilled a French version of the modified Schutte Emotional Intelligence Scale (Austin et al., 2004). The measure relies on a 5-point Likert-type scale ranging from 1 (strongly disagree) to 5 (strongly agree) on a 4l-item scale such as "I find it hard to understand the nonverbal messages of other people" and "I easily recognize my emotions as I experience them." This scale is based on the original model of Salovey and Mayer (1990) and captures three different dimensions of EI: Optimism/Mood Regulation, Appraisal of Emotion, and Utilization of Emotion. Austin et al. (2004) reported a good internal consistency of the scale with a Cronbach alpha of .85. The internal consistency of the French translation of the scale in our sample was lower than the one reported by Austin et al. (2004) with a Cronbach alpha of .75. To investigate this difference, additional tests (coefficient $\alpha$ ) were conducted by dropping each item and then recalculating the reliability estimate with the remaining items. These tests did not indicate that a particular item was causing the lower reliability, as the initial estimate of .75 did not vary.
Team EI was measured by aggregating individual scores of all the team members into a mean score for each team. To capture the influence that a single team member could have on the whole team or the impact of team diversity in EI, minimal and maximal scores, as well as the groups' variance were also taken into account for each team.

Group Cohesion. Group cohesion was assessed by a modified version by Dobbins and Zaccaro (1986) of Group Cohesiveness Scale, which was developed by Buchanan (1998). This scale relies on the multidimensional approach of cohesiveness proposed by Carron (1982). It is composed of seven items and uses a 5-point Likert-type scale $(1=$ strongly disagree to $5=$ strongly agree). Examples of items include "If given the chance, I would choose to leave my group and join another" and "I feel that I am really a part of my group." The summation of all seven items was used as the index of each participant's perception of cohesiveness. The average of the team members' cohesiveness scores was calculated to reflect cohesiveness at the group level. In the current sample, the coefficient alpha of the Group Cohesiveness Scale was .84 , whereas previous studies have shown that the scale has a coefficient alpha varying from .83 (Buchanan, 1998) to .91 (Dobbins \& Zaccaro, 1986).

Performance. Team performance was assessed in accordance with the four main dimensions identified by Savoie and Brunet (2000).

The group experience quality was measured using a self-reported job satisfaction questionnaire specifically designed for health care workers by different Belgian hospitals. The questionnaire is composed of 17 items and uses a 5-point Likert-type scale. It has been used for many years and has been validated by numerous studies (Langer, 2004). Examples of items include: "I have the opportunity to participate to training and learning programs in my team" and "I feel valorized in my work."

The team output measured in our sample was the quality of health care. Thus, each team was assessed three times by undercover observers on a scale of 33 objective criteria. This quality scale used in numerous Belgian hospitals includes criteria such as: "Before installing a transfusion, the nurse observes the necessary safety measures," "Workers don't wear any jewelry," and "The descriptive table of patients present in the unit is not readable by patients and visitors." The synthesis of the observations for each team was expressed into a total percentage of respected quality and safety criteria.

The team viability is the capability of the team to continue to function as a unit. To measure it with an objective indicator, the reasons of every departure in each team throughout the whole study length (4 months) were analyzed. Only considering the agents having left their team on their own request and excluding all the nonwanted departures (e.g., diseases and prophylactic spacing), a turnover rate has been created by dividing, for each team, the number of desired departures by the number of team members (e.g., a team with three 
desired departures and 18 members would have a turnover rate of .17).

Finally, the team legitimacy which corresponds to the supervisor's satisfaction was assessed by asking team supervisors (i.e., chief nursing executives) to complete a job performance questionnaire for each of the teams they were responsible for. This questionnaire was based on a previous job analysis conducted with human resources representatives, top managers, and team supervisors whose teams were not included in this study. Covering the main criteria upon which team supervisors usually assess their teams, the questionnaire is composed of 15 items and uses a 4-point Likert-type scale $(1=$ strongly disagree to $4=$ strongly agree) with no neutral position. Examples of items include "I often receive positive feedback form patients or visitors about this team" and "The team makes very few efforts to collaborate with other departments." The scale showed a good internal consistency with a Cronbach alpha of .85 .

\section{Results}

The correlation coefficients between team performance and total EI and subscales are reported in Table 1. As shown in Table 1, there is a positive correlation between the minimal score of Optimism/Mood Regulation and team output $(r=.52 ; P=.011)$, a positive correlation between the maximum score of Optimism/Mood Regulation in the team and team output $(r=.48 ; P=.019)$, and a negative correlation between the mean score of Appraisal of Emotion in teams and team output $(r=-.41 ; P=.049)$. Table 1 provides only partial support for Hypothesis 2. The EI dimension of mood regulation do relate to team output. However, the appraisal of emotion dimension has

Table I. Correlation Matrix of Team Emotional Intelligence and Team Performance Variables ( $N=23$ work teams)

\begin{tabular}{lcccc}
\hline & $\begin{array}{c}\text { Group } \\
\text { experience } \\
\text { quality }\end{array}$ & $\begin{array}{c}\text { Team } \\
\text { output }\end{array}$ & $\begin{array}{c}\text { Team } \\
\text { viability }\end{array}$ & $\begin{array}{c}\text { Team } \\
\text { legitimacy }\end{array}$ \\
\hline Overall El & & & & \\
Mean & .16 & .02 & -.04 & .27 \\
Minimum & -.15 & -.00 & -.38 & -.02 \\
Maximum & .15 & .02 & .21 & .19 \\
Variance & .23 & .03 & .30 & .03 \\
Optimism/Mood regulation & & & \\
Mean & .19 & .31 & -.08 & -.34 \\
Minimum & .15 & $.52 *$ & -.15 & .04 \\
Maximum & .33 & $.48 *$ & .15 & .35 \\
Variance & -.16 & -.36 & .11 & -.12 \\
Appraisal of emotion & & & \\
Mean & -.08 & $-.41^{*}$ & -.26 & .08 \\
Minimum & -.40 & -.40 & -.31 & -.24 \\
Maximum & .00 & -.16 & -.10 & -.05 \\
Variance & .36 & .05 & .11 & .10 \\
Utilization of emotion & & & \\
Mean & -.13 & .15 & .32 & -.29 \\
Minimum & -.25 & -.04 & .18 & -.11 \\
Maximum & -.03 & .15 & .25 & -.03 \\
Variance & .05 & .13 & .06 & -.11 \\
\hline P<.05 & & & &
\end{tabular}

${ }^{*} P<.05$.
Table 2. Correlation Matrix of Team Emotional Intelligence and Team Cohesiveness ( $N=23$ work teams)

Team cohesiveness

\begin{tabular}{ll}
\hline Overall EI & .39 \\
Mean & .12 \\
Minimum & .17 \\
Maximum & -.05 \\
Variance & \\
Optimism/Mood regulation & $.45^{*}$ \\
Mean & .22 \\
Minimum & .26 \\
Maximum & -.17 \\
Variance & \\
Appraisal of emotion & .33 \\
Mean & -.05 \\
Minimum & .30 \\
Maximum & .23 \\
Variance & \\
Utilization of emotion & -.30 \\
Mean & -.33 \\
Minimum & -.12 \\
Maximum & .24 \\
Variance & \\
\hline
\end{tabular}

${ }^{*} P<.05$.

the opposite relationship. These unexpected results will be discussed further in the discussion. Hypotheses 1, 3, and 4 were not supported.

The correlation matrix between team EI and group cohesion is presented in Table 2. An examination of Table 2 shows a significant positive correlation between the average score of Optimism/Mood Regulation in teams and cohesiveness $(r=.4501 ; P=.031)$. However, correlation between overall EI and cohesiveness is not significant $(r=$ .39; $P=.063)$. An additional analysis was thus used to investigate this relationship further. A new independent variable was created dividing our teams into two groups (low and high EI), using a median split $(M d n=146.42)$.

The difference between the two groups in term of EI was significant $(t=2, P<.0001)$. This analysis revealed a significant difference in cohesiveness between high-IE and low-IE groups $(t=3.43, P<.003)$. These results give support for Hypothesis 5 relating EI to group cohesion.

\section{Discussion}

Although the importance of EI for group effectiveness is often claimed, few studies have investigated this topic. The present data indicate that the relationship between EI and team performance is more subtle than first thought. Consistent with previous findings by Feyerherm and Rice (2002), the data are best understood by focusing on the details that isolate specific elements of performance and components of EI versus making a sweeping generalization that all components of EI relate to all measures of performance. Of the four main criteria of team performance, only team output (i.e., health care quality) is significantly correlated to two of three EI factors (i.e., Optimism/Mood Regulation and Appraisal of Emotion).

The minimum score of Optimism/Mood Regulation in team is positively related to health care quality. The lower 
the score of "the worst" team member regarding Optimism/Mood Regulation is, the lower the quality of health care provided by the whole team is. Conversely, the more the minimum Optimism/Mood Regulation increases, the more the quality of health care improves. This suggests that a very pessimistic member, who does not look for maintaining a positive emotional atmosphere for himself and the team, can solely affect the whole group dynamic and lower its outcome. Emotional contagion of this member's "bad mood" could provide a possible explanation of this finding. Indeed, negative affect like stress spreads out particularly easily among nursing teams through a contagion phenomenon (Bakker, Le Blanc, \& Schaufeli, 2005). The negative emotional state transmitted by this process could possibly alter team members' motivation to strictly respect safety and hygiene procedures, which in such an emotional atmosphere would be seen like tiring extra work.

Concurrent to the results above, this study also shows a positive relationship between the maximum score of Optimism/Mood Regulation in the team and the quality of the care. This seems to indicate that the higher the score of the "best" member of a team as regards Optimism/Mood Regulation is, the more the quality of health care increases in the whole unit. In line with the emotional contagion explanation mentioned above, one single member with a very high score on this dimension could, because of his or her optimism, frequent good mood, and concern for others' emotional well-being, improve his or her team's emotional atmosphere just by himself or herself. This team member would become a sort of emergent emotional leader, an "emotion manager" who pulls the team up. In such a positive ambiance, rigorously respecting safety and hygiene procedures could be perceived in a less constraining manner, and team members would therefore be more willing to make extra efforts. This hypothesis is akin to recent perspective on the role of emotion management on emergent leadership (George, 2000; Gond \& Mignonac, 2002).

Finally, the study shows a negative relationship between health care quality and the mean score of Appraisal of Emotion in teams. This surprising yet interesting result seems to indicate that the more team members in general were able to perceive and understand emotions, the less they provided high-quality health care. Why does good emotion perception lead to lower performance? There are at least three hypotheses. A possible explanation of this phenomenon could be that a team in which individuals are more sensitive to others' emotions is more people oriented than task oriented (according the famous managerial grid proposed by Blake \& Mouton, 1964). Therefore, energy and time used to take into account patients', families', or colleagues' emotions lower available resources for strictly respecting safety and hygiene procedures. Another possible explanation could be that members of a team who are particularly concerned with emotions are perhaps more indulgent with each other's mistakes (e.g., knowing that a colleague is feeling sad or not trying to "hurt his or her feelings," they would hesitate to make a remark about him taking liberties with the rules). Repeated uncorrected errors and justified mistakes would lead to a lower quality as regards health care security. At last, a third explanation could come from the fact that emotionally perceptive people appear to respond worse to stress than others do (Ciarrochi, Deane \& Anderson, 2002). Stressed team members would then pay less attention or care less for safety and hygiene norms. Further studies need to be done to test these three hypotheses and to clarify the mechanisms underlying this negative effect of emotional intelligence.

Concerning relationships between EI and cohesiveness, high-EI groups are significantly more cohesive than lowEI groups. This result is in line with previous findings (Barrick, Stewart, Neubert; \& Mount, 1998; Prati et al., 2003; Rapisarda, 2002). EI thus seems repeatedly to play a part in team cohesiveness. Moreover, beyond general EI, this study shows that Optimism/Mood Regulation is the most important subdimension to favor cohesion in a group. Team members' ability to seek for or to maintain positive emotional states in self and others helps them in getting along and pursuing common goals. However, some questions still need to be answered. Indeed, does EI influence group cohesion directly, through conflicts reduction, or by favoring close friendships? These questions still need to be investigated by future studies.

\section{Limitations of This Study}

Some limitations of the study could be mentioned. The first is the size of the sample (i.e., 23 teams). Although finding a great amount of comparable teams within a single hospital is quite challenging, having larger sample size of teams would have strengthened the impact of the study's results.

A second limitation of the study is the absence of assessment of personality factors. Indeed, even if Schutte et al. (1998) reported that their original Emotional Intelligence Scale was only significantly related to one of the Big Five personality dimensions (i.e., openness to experience) and not so highly as to be redundant, no data exist for the modified version of the scale used in this study. Thus, we cannot exclude a possible overlap between the present version of the EI scale and personality. Future studies on EI and team performance should include personality as a control measure to investigate further the specific impact of EI.

\section{General Conclusion}

Although not supporting the sweeping generalization that all components of EI relate to all measures of performance, this study clearly supports a relationship between Emotional Regulation and an important aspect of team performance (i.e., health care quality). Emotional Regulation may provide an interesting new way of enhancing patient/client outcomes and training future professionals to this ability could be especially fruitful. However, our study draws attention to the fact that not all subdimensions of EI are related to 
performance, and that Appraisal of Emotion could even be counterproductive. This finding needs to be replicated by future studies. Nevertheless, if negative impact of Appraisal of Emotion was confirmed, one can imagine how useless (or even dangerous in a hospital context) it is to train people to detect others' emotions. Without going this far, this study suggests to temper the numerous claims about the multiple benefits of EI in work teams. Organizations, thus, should at least question themselves about the specificities of their context and objectives before undertaking any expensive and time-consuming EI training program.

Conversely, EI could constitute an interesting new way of building cohesive teams in organizations. Including training on emotion regulation skills during teambuilding seminars might be more effective than bungee jumping to create long-term cohesiveness.

\section{References}

Abraham, R. (1999). Emotional intelligence in organizations: A conceptualization. Genetic, Social, and General Psychology Monographs, 125, 209-219.

Austin, E. J., Saklofske, D. H., Huang, S. H. S., \& McKenney, D (2004). Measurement of trait emotional intelligence: Testing and cross-validating a modified version of Schutte et al.'s (1998) measure. Personality and Individual Differences, 36, 555-562.

Averill, J. R., \& Nunley, E. P. (1992). Voyages of the heart: Living an emotionally creative life. New York: Free Press.

Bachman, J., Stein, S., Campbell, K., \& Sitarenios, G. (2000). Emotional intelligence in the collection of debt. International Journal of Selection and Assessment, 8, 176-182.

Bakker, A., Le Blanc, M., \& Schaufeli, W. (2005). Burnout contagion among intensive care nurses. Journal of Advanced Nursing, 51, 276-285.

Bar-On, R. (1997). The Emotional Intelligence Inventory (EQI): Technical manual. Toronto: Multi-Health Systems.

Bar-On, R. (2002). Bar-On Emotional Quotient Inventory (EQI): Technical Manual. Toronto, Canada: Multi-Health Systems.

Barrett G. V., Miguel R. F., Tan J. A., Hurd J. M. (2001). Emotional intelligence: The Madison Avenue approach to science and professional practice. Unpublished paper.

Barrick, M. R., Stewart, G. L., Neubert, M. J., \& Mount, M. K. (1998). Relating member ability and personality to work-team processes and team effectiveness. Journal of Applied Psychology, 83, 377-391.

Blake, R. R., \& Mouton, J. S. (1964). The managerial grid. Houston: Gulf.

Buchanan, L.B. (1998). The impact of Big Five personality characteristics on group cohesion and creative task performance. Unpublished doctoral dissertation, Virginia Polytechnic Institute and State University, Blacksburg.

Carron, A. (1982). Cohesiveness in sports groups: Interpretations and considerations. Journal of Sport Psychology, 4, 123-138.

Ciarrochi, J., Deane, F. P., \& Anderson, S. (2002). Emotional intelligence moderates the relationship between stress and mental health. Personality and Individual Differences, 32, 197-209.

Cooper, R. K., \& Sawaf, A. (1997). Executive EQ: Emotional intelligence in leaders and organizations. New York: Grosset/ Putnam.

Dobbins, G., \& Zaccaro, S. (1986). The effects of group cohesion and leader behaviour on subordinate satisfaction. Group and Organization Studies, 11, 203-219.
Dulewicz, V., \& Higgs, M. (2000). Emotional intelligence: A review and evaluation study. Journal of Managerial Psychology, 15, 341-372.

Dyer, W. (1995). Team building: Current issues and alternatives ( $3 r d$ ed.). New York: Addison Wesley.

Feyerherm, A. E., \& Rice, C. L. (2002). Emotional Intelligence and Team Performance: The good, the bad and the ugly. International Journal of Organizational Analysis, 10, 343-362.

George, J. M. (2000). Emotions and leadership. The role of emotional intelligence. Human Relations, 53, 1027-1044.

Gerits, L., Derksen, J. J. L., Verbruggen, A. B., \& Katzko, M. (2005). Emotional intelligence profiles of nurses caring for people with severe behaviour problems. Personality and Individual Differences, 38, 33-43.

Goleman, D. (1995). Emotional intelligence. New York: Bantam Books.

Goleman, D. (1998). Working with emotional intelligence. New York: Bantam Books.

Gond, J.-P., Mignonac, K. (2002). Emotions, leadership et évolution des conditions d'accès aux postes de direction. Note LIRHE, no. 358 (02-2), 24 pp.

Hackman, J. R. (1987). The design of work teams. In J. Lorsch (Ed.), Handbook of organization behavior. Englewood Cliffs, NJ: Prentice Hall.

Hackman, J. R. (1990). Conclusion: Creating more effective work groups in organizations. In J.R. Hackman (Ed.), Groups that work (and those that don't). San Francisco, CA: Jossey-Bass.

Hay Group. (2000). Emotional intelligence: A "soft" skill with a hard edge. http://ei.haygroup.com/about_ei/.

Janovics, J., \& Christiansen, N. D. (2001). Emotional intelligence at the workplace. Paper presented at the 16th Annual Conference of the Society of Industrial and Organizational Psychology. San Diego, CA.

Jordan, P. J., \& Troth, A. C. (2002). Emotional intelligence and conflict resolution: Implications for human resource development. In J. L. Callahan \& E. E. McCollum (Eds.), Advances in developing human resources, special edition perspectives of emotion and organizational change, vol. 4.

Jordan, P. J., \& Troth, A. C. (2004). Managing emotions during team problem solving: Emotional intelligence and conflict resolution. Human Performance, 17, 195-218.

Jordan, P. J., Ashkanasy, N. M., Härtel, C. E. J., \& Hooper, G. S. (2002). Workgroup emotional intelligence: Scale development and relationship to team process effectiveness and goal focus. Human Resource Management Review, 12, 195-214.

Katzenbach, J., \& Smith, D. (1994). Les équipes haute performance: Imagination et discipline. Paris: Dunod.

Kooker, B. M., Shoultz, J., \& Codier, E. (2007). Identifying emotional intelligence in professional nursing practice. Journal of Professional Nursing, 23, 30-36.

Landa, J. M. A., Lopez-Zafra, E., Martos, M. P. B., GuilarLuzon, M. (In press). The relationship between emotional intelligence, occupational stress and health in nurses: A questionnaire survey. International Journal of Nursing Studies.

Langer, S. (2004). Utilisation d'un outil d'évaluation de la satisfaction au travail du personnel de soins: Expérience menée au C.H.R. de liège. Mémoire de licence en Science de la Santé Publique non publié. Liège: Université de Liège.

Mcqueen, A. C. H. (2004). Emotional intelligence in nursing work. Journal of Advanced Nursing, 47, 101-108.

Mayer, J. D., Caruso, D. R., \& Salovey, P. (2000). Selecting a measure of emotional intelligence. In R. Bar-On \& J.D.A. Parker 
(Eds.), Handbook of emotional intelligence. San Francisco, CA: Jossey-Bass.

Mayer, J. D., Salovey, P., \& Caruso, D. R. (2000). Models of emotional intelligence. In J. Sternberg (Ed.), Handbook of intelligence. Cambridge, England: Cambridge University Press.

Mayer, J. D., \& Salovey, P. (1997). What is emotional intelligence? In P. Salovey \& D. J. Sluyter (Eds.), Emotional development and emotional intelligence: Educational implications. New York: Basic Books.

Mayer, J. D., \& Stevens, A. (1994). An emerging understanding of the reflective (meta-) experience of mood. Journal of Research in Personality, 28, 351-373.

Mayer, J. D., DiPaolo, M. T., \& Salovey, P. (1990). Perceiving affective content in ambiguous visual stimuli: A component of emotional intelligence. Journal of Personality Assessment, 54, 772-781.

Miville, M. L., Carlozzi, A. F., Gushue, G. V., Schara, S. L., \& Ueda, M. (2006). Mental health counsellor qualities for a diverse clientele: Linking empathy, universal-diverse orientation, and emotional intelligence. Journal of Mental Health Counseling, 28, 151-165.

Montes-Berges, B., \& Augusto, J. M. (2007). Exploring the relationship between perceived emotional intelligence, coping, social support and mental health in nursing students. Journal of Psychiatric and Mental Health Nursing, 14, 163-171.

Petrides, K. V., \& Furnham, A. (2000). On the dimensional structure of emotional intelligence. Personality and Individual Differences, 29, 313-320.
Petrides, K. V., \& Furnham, A. (2003). Trait emotional intelligence: Behavioural validation in two studies of emotion recognition and reactivity to mood induction. European Journal of Personality, 17, 39-57.

Prati, L., Douglas, C., Ferris, G. R., Ammeter, A. P., \& Buckley, M. R. (2003). Emotional intelligence, leadership effectiveness, and team outcomes. International Journal of Organizational Analysis, 11, 21-40.

Rapisarda, B. A. (2002). The impact of emotional intelligence on work team cohesiveness and performance. International Journal of Organizational Analysis, 10, 363-379.

Savoie, A., \& Brunet, L. (2000). Les équipes de travail: Champ d'intervention privilégié pour les psychologies. In J.-L. Bernaud \& C. Lemoine (Eds.), Traité de psychologie du travail et des organisations. Paris: Dunod.

Salovey, P., \& Mayer, J. D. (1990). Emotional intelligence. Imagination, Cognition and Personality, 9, 185-211.

Schutte, N. S., Malouff, J. M., Hall, L. E., Haggerty, D. J., Cooper, J. T., Golden, C. J., et al. (1998). Development and validation of a measure of emotional intelligence. Personality and Individual Differences, 25, 167-177.

Thoits, P. A. (1989). The sociology of emotions. Annual Review of Sociology, 15, 317-342.

Weisinger, H. (1998). Emotional intelligence at work: The untapped edge for success. San Francisco, CA: Jossey-Bass.

Zeidner, M., Matthews, G., \& Roberts, R. (2004). Emotional intelligence in the workplace: A critical review. Applied Psychology: An International Review, 53, 371-399. 